\title{
Public Interest and the Theory of Librarianship
}

\section{By JOSEPH Z. NITECKI}

THE DIsCussion of the relationship between the public interest and library objectives in this paper rests on the following two premises: (1) The American library constitutes an integral part of the structure of its own society; it originated and grew in response to that society's needs. (2) The structure of American society is a political democracy.

The democracy is here defined in terms of a variety of highly diversified and cross-related individual interests, which together create a pattern of multigroup interests, integrating the similar interests within each group, and segregating between these groups in terms of their conflicting interests. The method of accommodating all of these interests in democracy is political, based on competition between the groups for the sanction of their objectives by society at large. Thus, in a political democracy no individual, nor any group of individuals, is free from these powers of society, nor can it avoid its consequences. Therefore, the library, as a service institution, is the subject of political pressure, but at the same time it becomes a political institution with its own pressures used in the process of implementing its services.

\section{The Nature of the Stimulus}

The pressures on the library are of varying degrees, coming from various directions and requesting different kinds of services. Thus, the role of the library as a social institution is to provide and to develop the means for a better bookreader relationship, in which different readers, or groups of readers, expect dif-
Mr. Nitecki is a librarian of the Woodrow Wilson Branch of the Chicago City Junior College. This essay is a revised and abbreviated version of Chapter III of the author's "The Concept of Public Interest in the Philosophy of Librarianship; the Implications of a Multiple Approach" (Unpublished Master's paper, Graduate Library School, University of Chicago, 1963). The original paper contains, in addition, an extensive discussion of the contemporary theories of public interest and a review of recent library literature illustrating the application of the view here described to problems of modern librarianship.

ferent kinds of books for different purposes.

All of the group-interest pressures imposed on the library may be classed into one of three basic kinds: (1) requests for service, i.e., to provide a given book; (2) requests for education, i.e., to provide a book on a given subject; (3) requests for arbitration, i.e., to provide either (a) controversial books on a given subject, or, (b) books on a controversial subject.

The convergence of these three types of demands is illustrated in Figure 1.

In requesting service, a patron knows what he wants; in demanding education, he wants to know what kind of book he should get; while in asking for arbitration, he expects assistance in choosing between opposing wants.

Each of the above requests constitutes a pressure for service which increases in proportion to the number of such requests made. The pressure may be measured in terms of an aggregate of individual re- 
Group interest A

(e.g., for service)

Group interest C

(e.g., for mediation)

FIg. 1.-Differing motivations for demands on the library.

quests, or as a definite demand made collectively by a group in society. In addition, such requests may be positive, for a specific kind of book (fulfilling the service), or negative, against a particular service offered by the library.

As an example of the way the different pressures might work for or against a particular book in different situations, let us consider a book on birth control. Purely from the standpoint of efficient service, it might be expected in a medical library but would only clutter up the shelves in an engineering library. As an educational instrument, it might be held to have intrinsic value by a population expert but held to be pernicious by a devout Catholic. The subject is at this day controversial, and some segments of the community might approve of its being suggested by a reader's adviser while others might condemn the suggestion. From the standpoint of the public, one form of demand is charged with about as much emotion as another. While the radical right wing group is excessive in its denunciation of books alleged to be communist, probably no bitterness exceeds that of a scholar who finds the library has failed to acquire a book he thinks it ought to have. Those who are devoted to efficiency feel as strongly about it as those who are concerned with education or arbitration.

The library, as an institution of the whole community, can neither ignore nor succumb to any of these group pressures. A kind of response to these interestswhich in itself is a sine qua non of library existence-constitutes the basis for the theory of librarianship, while its practical application implies an active participation in the affairs of society, not only in responding to, but also in imposing on society a new set of pressures. Thus the library, in fulfilling its obligations, becomes an interest group by itself, with its own political powers in the areas of serving, educating and mediating among the needs of the readers.

A clear perception of these influences upon society is needed not only for the purpose of defining the role of the librarian, but also in establishing the degree of library involvement. On the other hand, a misconception about these pressures leads to a confusion of goals and to inefficiency in library performance. One of the main reasons for this is a seemingly confusing maze of relationships emerging from the dual position of the library as a recipient and at the same time as a transmitter of different interest-pressures. Juxtaposed, they may be represented by Figure 3 .

As seen in Figure 3, each of the basic demands made upon the library (for service, education, arbitration) is met by a specific and direct response (provision of requested, selected, or balanced material). However, none of the above functions operates in isolation, and consequently none of the services is limited to a singular effect. Thus, for example, supplying a requested book most probably also affects the educational status of its reader, at the same time strengthening or softening his stand on a given controversial issue. But even more important and significant is the orientation of the librarian himself. If his conception of li- 


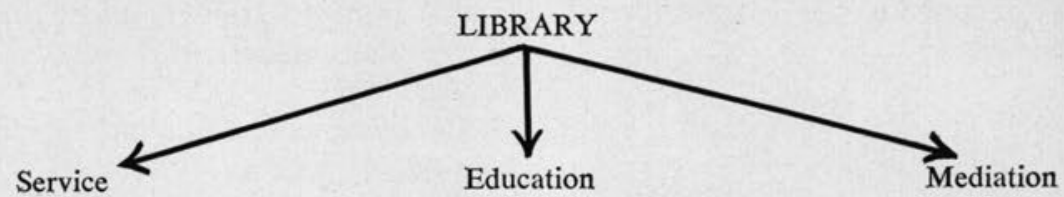

FIG. 2.-Differing responses to the demands on the library.

brary objectives is limited to, or even merely inclined toward, one of the three functions indicated in the above diagram, his performance will produce an entirely different result. If, for instance, the librarian considers himself first and foremost an educator, he will tend to provide preselected material (determined by his conception of educational goals) not only in response to requests for educational materials, but also in fulfilling library obligations to provide books asked for (by trying to suggest a "better" book as a substitute), as well as in assisting the reader to make up his mind on controversial issues (by doing it for the reader).

This kind of interrelationship is not mere speculation. The literature of the profession provides an ample number of examples of attempts to solve precisely these difficulties in the practice of librarianship. A more detailed examination of the diagram above may prove useful in clarifying to some extent at least, the relationship between expectations and performance in library services.

\section{The Mechanism of Response}

First, let us enumerate some obvious internal relations implied in the abovementioned diagram. These can be grouped into library obligations and library limitations:

A. Three library objectives:

1. To respond to the demand for service

2. To respond to the demand for education

\section{GROUP INTEREST}

specific demand:

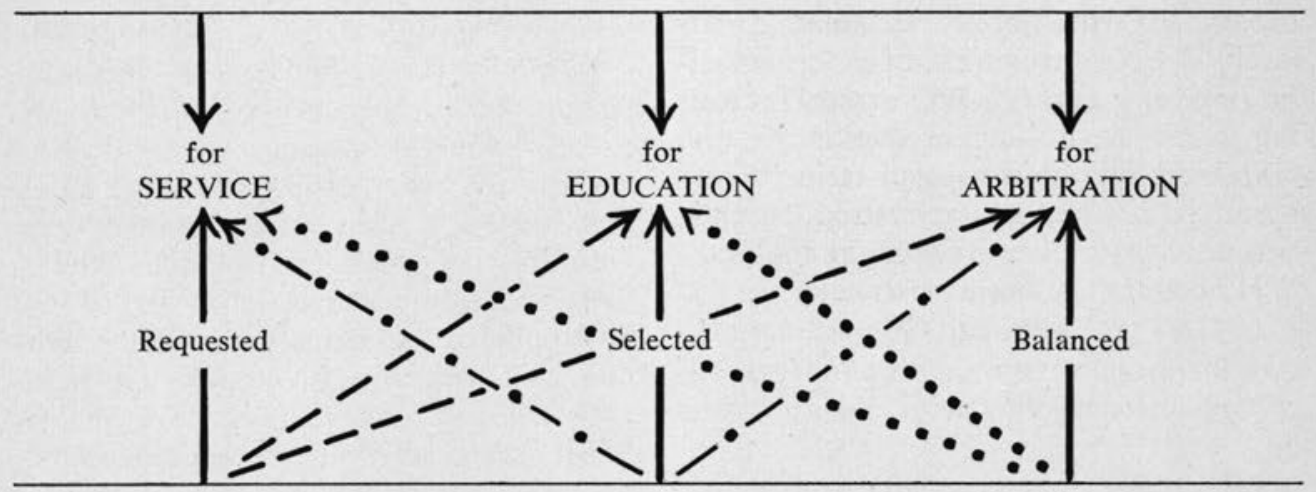

provision of reading material:

LIBRARY SERVICE

FIG. 3.-Interrelationship between demands of group interests and library services. 
3. To respond to the demand for mediation

(These relations are indicated in the diagram as uninterrupted lines.)

B. Six library limitations:

1. Not to provide service only, when asked for education

2. Not to provide service only, when asked for arbitration

3. Not to provide education only, when asked for service

4. Not to provide education only, when asked for arbitration

5. Not to provide arbitration only, when asked for service

6. Not to provide arbitration only, when asked for education

(These services are shown in the diagram by interrupted lines.)

In the objectives the stress is on the obligation of the librarian to respond to these requests, i.e., the concept of always trying to satisfy all the needs of a reader. The limitations, on the other hand, constitute an argument against a narrow specialization (i.e., too limited a response) as evident in the two levels of philosophical response in librarianship:

a. The personal philosophy of a librarian who is oriented and dedicated to one of the goals of librarianship exclusively (e.g., a cataloger, a reference librarian, or a library administrator) resulting in a bias, evident in considering the remaining two objectives in terms of the preferred one (e.g., an overstress on classificatory problems, overlooking the practical needs of the library user, etc.).

b. The institutional philosophy, in which the whole library's operations are defined in terms of one of the functions only (e.g., circulation, public and school library), and in resisting demands which formally should be met by other types of libraries.

A comparison of library obligations and limitations yields the following nine library functions:
1. To store materials required for service

2. To store materials required for arbitration

3. To store materials required for education

4. To aim at education by selected service

5. To aim at education by providing relevant instruction

6. To aim at education by providing appropriate data for arbitration

7. To organize a balanced service

8. To organize a balanced education

9. To organize a balanced mediation.

This tabulation illustrates an approach suggested in this paper, in which the philosophy of librarianship is formulated in terms of three basic kinds of decisionmaking processes, diffentiated by the three objectives of librarianship, i.e., to collect, to educate, and to mediate.

It is proposed to show that the shift of emphasis from the goals of librarianship per se, into their functional and specific aspects (i.e., limited), may contribute toward the clarification of the relationship discussed. That is, in anticipating readers' requests, the librarian organizes his collection in terms of the nine theorems formulated above, by aiming at storing the material, which is selected and organized in such a way as to provide sufficient assistance in response to the requests for service, education, and arbitration. In consequence of such an approach, when responding to a definite request, the librarian can provide a quick and efficient service by relying on a wellorganized collection (i.e., planned, classified, and administered in terms of the three objectives, namely service, education and arbitration). Similarly, in planning the future development of the library or in performing the reference function, the librarian is not biased by one objective, ever-influencing the three functions, but considers each of the objectives in terms of their corresponding functional aspects.

Consequently, each function and its 


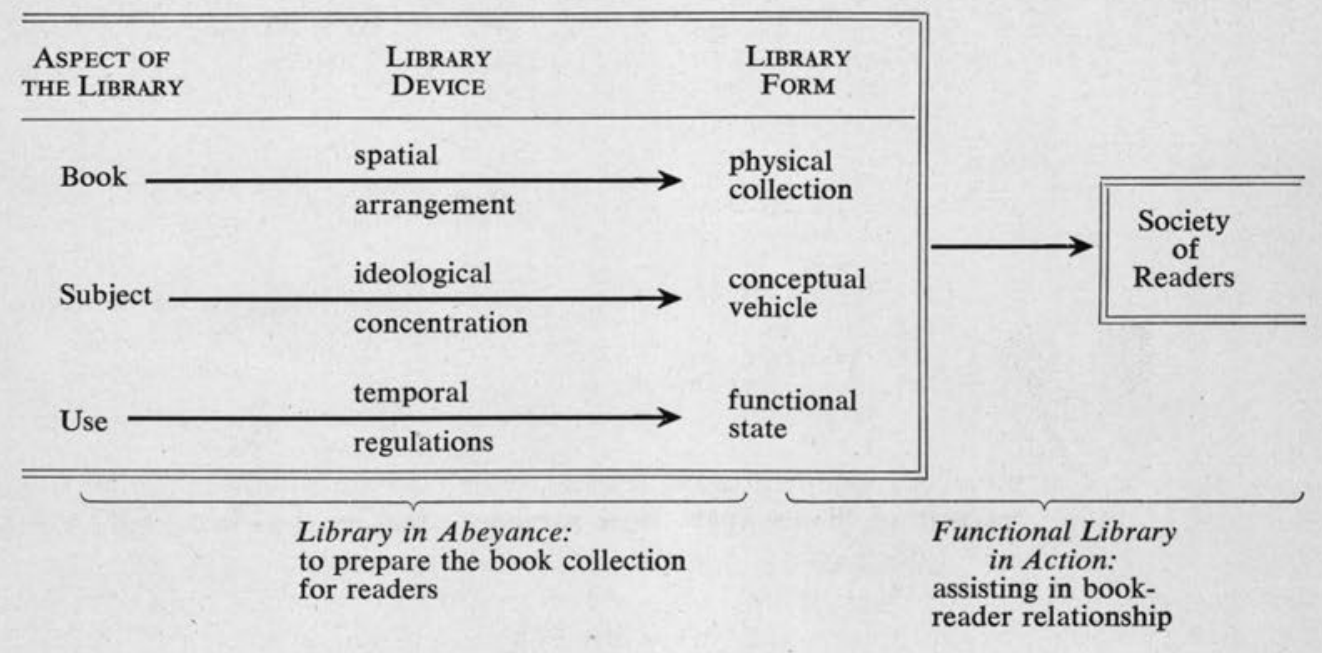

FIG. 4.-The contribution of three functional philosophies to library unity.

corresponding decision-making process is essential in any library. The library specialization, that is, the preferential treatment of any one of these functions, is adjusted to the needs of a specialized reader of the library by changing the proportions of the three objectives, but not by eliminating them altogether. Thus, for example, in the specialized medical library, a number of various, unrelated titles and subjects will not be included in the collection, although each of those which are in the library will be used for each of the three purposes, i.e., to provide concrete data, to explain their meaning, or to relate their significance to other facts.

Such a philosophy of librarianship presupposes a theoretical formulation which would relate the objectives of the library to its operations in a consistent, logical pattern.

The view expounded in this paper consists of the differentiation between three philosophical premises:

1. The procedural, concerned with library technology ("storing"), i.e., the arrangement of library resources for determined purposes.

2. The conceptual, concerned with library planning ("aiming at"), i.e., the formulation of specific library objectives or purposes.

3. The contextual, concerned with the administration of library services ("balancing"), i.e., providing required service.

Thus, although in practice the library specialization may be manifold and differentiated by the form and/or the functions performed, the theory of librarianship in its threefold formulation incorporates all of the three functions covering all of the forms of service.

However, it is essential to note that in this theoretical formulation:

procedure does not imply routinism, planning does not imply dogmatism, organization does not imply bureaucracy.

That is, the theory proposed is not frozen by conventional, authoritative, or unvarying mechanical interpretations. Each of the three functions singled out is differentiated in terms of different roles called for, but within each of these roles there is leeway in the method of performing these roles.

Furthermore, although all of the three functions are mutually inclusive in the 
TABLE 1

Different Philosophical Premises Illustrated In Library Technical Processes

\begin{tabular}{|c|c|c|c|c|}
\hline \multicolumn{3}{|c|}{ INTERNAL Motive } & \multirow{2}{*}{$\begin{array}{c}\text { EXTERNAL } \\
\text { MANIFESTATION }\end{array}$} & \multirow{2}{*}{$\begin{array}{c}\text { END } \\
\text { RESULT }\end{array}$} \\
\hline Premise & & Device & & \\
\hline $\begin{array}{l}\text { Procedural . } \\
\text { Conceptual . } \\
\text { Contextual }\end{array}$ & . & $\begin{array}{l}\text { Classification system } \\
\text { Code for consistency } \\
\text { of application } \\
\text { Manual of operation }\end{array}$ & Efficiency & $\begin{array}{l}\text { Functional } \\
\text { Collection }\end{array}$ \\
\hline
\end{tabular}

sense that each of them is related to the problem of library goals, book arrangement, and administration, they do not necessarily lead to eclecticism. That is, although individually each approach is in a way incorporated in the other two approaches, none of them alone-in this implied form - determines the goals of decision-making processes but merely participates in them as an organic part of the whole process. However, once the objectives are formulated, the most appropriate decision-making approach is chosen, and then it operates independently, excluding the other two approaches as self-contradictory.

To illustrate this principle, we will use an example of the application of this theory to the roles called for in the activities of technical processes of the library. Although technical processes involve mainly a procedural aspect of librarianship, the other premises are active here, too. The conceptual approach is involved in planning and the contextual in the organization of the work.

In Table 2 we notice that the main manifestation of technical processing is the provision of efficient and smooth op-

TABLE 2

EFFECTS OF FAILURE TO CONSIDER Overall ObJectives

\begin{tabular}{|c|c|}
\hline Decisions Based Exclusively on & \multirow{2}{*}{$\begin{array}{l}\text { Effects on the Process } \\
\text { Over classification }\end{array}$} \\
\hline Procedural system & \\
\hline Conceptual consistency & Inflexibility \\
\hline Contextual manual & Artificiality \\
\hline
\end{tabular}

eration which in turn will increase the functional aspects of the collection. Yet this over-all procedural approach consists of a number of internal objectives of varied character. The efficiency of operation is conceived in terms of a systematic classification (procedural aspect), its consistency (which is a conceptual goal aimed at), and a set of arbitrary decisions needed in controversial or conflicting situations (e.g., formulated in the library's manual of operation, which is to be consulted in cases of conflict between the accepted procedure and exceptional situations-a contextual mediating device).

In this example we can see the distinction between the internal motives and the resulting external process. If in this scheme the internal stimula were not subjugated to the over-all objectives, the process shown in Table 2 would result.

That is, if each of the internal motives were independently responsible for the initiation of the process of operation, the collection would reflect the evils of notso-unreal exaggerations, for example: the use of long and minutely subdivided call numbers in a relatively small library; lack of flexibility in not accommodating for new subjects not provided for in the printed classification schedule; and the artificiality created by rules made to fit the needs of day-to-day operations.

The illustration of the relationship between the relative roles of the different approaches can be extended to the library situation in general. Although each of 
these philosophies operates autonomously within the library organization they do not destroy the unity of the library.

In Figure 4 we can see the analogy to the situation of a specific aspect of library operations, illustrated by the previous diagram, by distinguishing between the library form, which is a set-up, a kind of organizational blueprint, and the functional library, conceived in terms of its operations.

And again, in considering the library's dormant characteristics, we distinguish the internal differentiation between its physical, conceptual, and functional characteristics. That is, in each library organization we have to make a distinction between the problems related to the physical book itself, to its subject, and to its use, each posing different problems and objectives. Consequently, different theories are needed to formulate these different operations. None of the definitions of a part of the library would sufficiently define the whole library (i.e., the library defined as a storage of books, as a conceptual vehicle, or as a functional unit, exclusively). Only if combined in cooperative functioning can these aspects fulfill library expectations. Thus we conclude with a restatement of what was the opening assumption of this paper. The role of the library in a society implies an interplay of different factors in an overall effort of the library to sustain its existence. In other words, the library as an institution is not taken for granted, and its place in society is not sanctioned by external reasons, independent of itself. On the contrary, its constitution is determined by the rights and obligations which emerge out of the competitive situation among all the social institutions striving for their rights to participate in the life of society.

The supreme justification for such existence and the relative importance of the library in the society are determined by the degree of its involvement in the affairs of the society. The means of participation are political in nature, measured in relative terms by pressures imposed on the library by the group interests and the power of library influence over these group interests. Library achievement is determined by the procedural, conceptual, and contextual development simultaneously; the more efficient the procedure, the better the possibilities of achieving its objectives, and the more respected the mediative character of the library, the more powerful its influence upon society.

\section{The Criteria in Differentiating among the Three Philosophical APPROACHES}

The next step, after defining the mechanism of the library structure in dealing with various pressures, is to analyze the pressures themselves. As we have already noted, these pressures are used in a democratic society in order to promote the specific interests of various groups in

TABLE 3

The Evolving OBJectives of the LibraRy

\begin{tabular}{|c|c|c|c|}
\hline $\begin{array}{l}\text { Approximate Time } \\
\text { Sequence }\end{array}$ & 17-18 Centuries & 18-19 Centuries & 19-20 Centuries \\
\hline $\begin{array}{l}\text { Ultimate goals } \\
\text { Policies }\end{array}$ & $\begin{array}{l}\text { To read } \\
\text { Book availability }\end{array}$ & $\begin{array}{l}\text { To educate } \\
\text { Book usefulness }\end{array}$ & $\begin{array}{l}\text { To mediate } \\
\text { Book availability \& use- } \\
\text { fulness for diversified } \\
\text { purposes }\end{array}$ \\
\hline Areas of achievement & Storage & $\begin{array}{c}\text { Internal library } \\
\text { organization }\end{array}$ & $\begin{array}{l}\text { Cooperation between } \\
\text { libraries }\end{array}$ \\
\hline $\begin{array}{l}\text { Public reaction } \\
\text { Library image }\end{array}$ & $\begin{array}{l}\text { Toleration of the } \\
\text { library } \\
\text { Ornament }\end{array}$ & $\begin{array}{l}\text { Acceptance of the } \\
\text { library } \\
\text { Utility }\end{array}$ & $\begin{array}{l}\text { Participation in the ac- } \\
\text { tivities of the library } \\
\text { Tool }\end{array}$ \\
\hline
\end{tabular}


society. A given group interest, when approved by the consensus of the majority of the members of the community involved, receives a public sanction which entitles it to be considered as an interest of the society at large, i.e., a "public" interest-thus, in turn, becoming a legitimate concern of the social institutions which are responsible for meeting such public demands.

As we have already noted, the social institutions approach the problem of fulfilling these needs by developing three different kinds of attitudes, attempting to meet the three basic characteristics inherent in these public interests-namely, to provide the proper conditions needed to (a) satisfy the needs which are already formulated, (b) to assist in the expression of needs which are not fully understood by the reader, and finally (c) to mediate among conflicting needs. We have argued that each of these requirements is generically autonomous, calling for an independent theory of its own, and we concluded that only the three approaches combined together in a cooperative interaction can do justice to the variety of public interests in a political democracy.

The problem we are facing in this sec- tion is to establish a set of principles by which we could differentiate these services in librarianship.

We propose to use three kinds of threads unifying the theory of librarianship: the role of the librarianship, its goals, and the kind of decision-making process developed. Each of these aspects should be considered in terms of the concept of public interest as it is interpreted by the three theories of public interest. This will be attempted by comparing the meaning of "public" and of "interest," and the relationship between them, as represented by the definition of public interest proposed by each of these theories.

Figure 5 is the tabulation of the criteria as an illustration of each of the theories of public interest. ${ }^{1}$

The characteristics defining the procedural, conceptual, and contextual theo-

\begin{abstract}
${ }^{1}$ For the sake of elarity, we abstract each of the three approaches from the totality of library functions, describing each in isolation and in terms of its own primary characteristics. Thus, by discussing proceduralism, for example, we refer to these aspects which differentiate it internally from the other two approaches. A person who in a given decision-making process utilizes the procedural eriteria, is, at that time, called a proceduralist in a positive sense; if, however, he extends procedural principles to situations warranting conceptual or contextual considerations, then he becomes a proceduralist in a negative sense.
\end{abstract}

\section{Public Interest:}

\section{"Public" \\ "Interest"}

Defined as

Philosophy of

Librarianship:

Goal .

Role

Process

\begin{tabular}{|l|}
\hline Procedural \\
\hline $\begin{array}{l}\text { Traditional } \\
\text { Legal } \\
\text { Norms }\end{array}$ \\
\\
$\begin{array}{l}\text { Preservation } \\
\text { Custodianship } \\
\text { Technical }\end{array}$ \\
\hline
\end{tabular}

FIg. 5.-The philosophy of librarianship compared to the theories of public interest.*

* For the bibliography concerning the themes of public interest discussed in this essay, see the author's original paper, pp. 131-40, and especially:

a. Glendon Schubert, The Public Interest: A Critique of the Theory of a Political Concept (Glencoe, III.: The Free Press, 1960), for his threefold classification of theories of the public interest;

b. Oliver Garceau, The Public Library in the Political Process: A Report of the Public Library (New York: Columbia University Press, 1949), for the historical generalization of library goals ;

c. Howard R. Smith, Democracy and the Public Interest. University of Georgia Monographs, No. 5 (Athens: University of Georgia Press, 1960), for the analysis of the role of the public interest in a political democracy. 
ries of public interest can be briefly summarized as follows:

a. Proceduralism defines the public interest as a means, i.e., the norms which determine the ways of achieving the overall goals of the society. In this definition, the "public" is considered as an active manifestation of the values established in the span of its historical development. It is therefore viewed in the framework of traditions, which not only formulated the "public" itself, but also its mores, i.e., the basic values which are accepted and embodied in the fundamental moral fiber of the society. And finally, the proceduralist is not concerned with the search for these values. They are already stated for him in the legal code, regulating the coexistence of the group interests within the society. Thus, any group interest which is legal becomes also "public" by contributing to the development of traditionally established values. The role of the proceduralist is therefore to assist the realization of these values by providing the best possible means of their attainment.

This formulation parallels the procedural philosophy of librarianship, stressing the importance of technical processes in preserving the cultural heritage of the society. The procedural librarian is therefore a custodian of the past; his goal is best fulfilled by protecting the collection in such a way that it will be simultaneously accessible for use by the contemporary public and preserved for public use in the future. His attitude toward public interest is best defined in terms of the procedural theory of public interest.

$b$. The conceptual philosophy of public interest rests on the acceptance of an ideal, "durable" conception of the public, which becomes a model or "form" for the aspirations of society. For this reason, the conceptualist rejects the significance of any specific public interest, if it leads to a preferential treatment of the interests of one group in society. To him, all the conflicts between segments of society should be resolved in terms of the interests of the whole society. Consequently, his goal is to contribute toward the unification of society by redirecting and re-interpreting group interests in terms of the ultimate interests of a society. In short, his function is to educate.

A corresponding role of the librarian is expressed in the educational aspect of librarianship, which is aimed at interpretation of the cultural values of society. The process involved in this conceptual function of the library calls for a selection of suitable reading materials for the library collection and its actual use. The selection is based on a value concept of "suitable" and "proper" material, and therefore it is ethical in essence. The conceptual librarian is a planner in the sense that he is concerned about the "ideal" kind of library collection and services. His role is to determine the goals of librarianship, transcending the immediate interests of any segment of the public.

c. The contextual interpretation of public interest is exclusively concerned with the specific group interests as they emerge in actual conflicting situations. The goal of the contextualist is to assist in resolving the conflict, and not to suppress the interest. In other words, he conceives the public as an aggregate of individual group interests, each striving toward the achievement of its specific interests, while the society, as conceived by him, is the aggregate of these interests at any particular moment. The public interest should be attended to, not because it is a common good, but because it leads toward it. It formulates the attitudes which in turn determine the co-existence of multiple interests. The role of a contextualist is to encourage the expression of these interests and to assist in resolving the ensuing conflicts. In librarianship, this is precisely the function of the library administrator who strives to establish library resources which are open to all group interests and which are suffi- 
ciently varied to meet a variety of conflicting demands.

In achieving his objectives, the contextualist relies on a political process determining the proper course of action in terms, not of efficiency (proceduralism) or moral values (conceptualism), but of the consensus of the majority of the library public. Since consensus has to be won, the librarian has to lead the fight for library approval and consequently is concerned with problems of promotion, public relations, etc.

\section{QUEST FOR PARTICIPATION}

The concept of involvement is a prerequisite of the notion of public interest. The organization which does not actively participate in solving the contemporary problems of its society, such as, for example, the Museum of Natural History, is relatively free from the direct influence of public interest pressures upon its activities. Such was also the case of the library in the beginning period of its development. In the premodern stage of librarianship, the librarian combined the roles of a scholar and a custodian together with that of a bibliophile, and the library collection was a result of the demands made on him for books and their content. In the modern period the trend is reversed, since it is the librarian who imposes his activities upon the society by developing different kinds of services in anticipation of a variety of expected demands for his services.

The following outline summarizes the development of the library's objectives in the last four centuries. In Table 3 we may notice the emerging over-all pattern of modern librarianship, beginning with the stress on book content, through attempts to enlarge the scope of its influence into an integrative role of the library as a cultural unit, constituting an organic part of the society.

The growth of the modern theory of librarianship may be characterized as a gradually emerging concept of library in- volvement in the affairs of its community. It began with the emphasis on the value of reading-in-itself which was a belief closely related to the dominant philosophy of that period, stressing the importance of the humanistic notion of selfimprovement of individual members of the community, which together would strengthen the general will of the society. It was the period of enlightenment in both political and library philosophies.

The second library period, characterized by the progress made in the improvement of library techniques, was again in accord with the common belief in the precepts of natural law, which by the nature of their "inevitability" imposed a harmony of all interests in the uniformly organized society. In librarianship, this was a period in which an effort was made to propagate reading as a cure for social maladies, on the assumption that all such maladjustments are the result of unintentional violation of the laws of nature.

In contemporary political theory, the stress is on the relativism of goals demanding a correspondingly relativistic method of achieving them. In both the political and library theories of public interest, it means the maximization of the participation of social institutions in the actual life of society, aiming at the minimization of conflicts. This is achieved by searching for a common ground of understanding. In both cases, it is a period of complete involvement in the affairs of society, rejecting any evaluation of its problems from the position of an outsider.

The stress on the ideals of conceptualism was developed in a historical period of great optimism and faith in human potentialities, the approach of proceduralism reflected the age of scientific preoccupation in improving the physical aspects of human conditions, while the contextual stress on the problem-solving method of today is formulated in the contemporary language of relativism. Therefore, both the political theory of public interest and

(Continued on page 325 ) 
have been rewritten. As in the older volume, articles are relatively brief, but clearly and objectively written. There are only rare bibliographic citations, but contributors are indicated by initials. The principal departure in the new work is the omission of biographical articles as such, as well as the several appended tables of sovereigns and other officials.

British Political Facts, though limited to

\section{PUBLIC INTEREST . . .}

(Continued from page 278)

the philosophy of library science were, and are, the semantic expressions of concurrent ideas. Both expressed the general philosophy of their time.

\section{PRACTICAL IMPLicATIONS}

Concluding this essay, we are faced with the perennial question which arises in connection with any theoretical work, especially in a predominantly practical field such as library science-the question of relevance: "So what?"

The basic approach of this paper consists in a search for a unifying principle - for consistency-to prevent internal contradiction between various specialized activities within the library. We have considered in this paper the peculiar nature of library operations, characterized by both an internal diversification of roles and at the same time a unification of these library activities into a general library service to society. Thus, the specialist must apply his specific approach within the context of a general library operation, while a general theory of librarianship must both include a formulation of the basic postulates of the discipline itself, which distinguish it from other disciplines and at the same time account for the existence of a number of subtheories, reflecting the diversified objectives of library specializations.

An awareness of unity is expressed in the over-all functioning of the library in society, while competition between the the twentieth century, is a collection of considerable amount of ready information, tabular in form except for some explanatory notes and introductions. The twenty chapters treat such materials as ministries, parties, sovereigns, elections, civil service, treaties, public communication, and a wide selection of economic and social statistics.J.N.W.

various specialized approaches enriches the dynamic growth of the discipline, resulting in an efficient, valuable, and useful service to the reader.

This view of the library can be applied by the librarian in his dual role as both recipient and initiator of social pressures. The library will not only serve the interests of its own community but also contribute to the development of new interests. Thus, although the library is primarily an institution designed to serve the reader, its contemporary position in society suggests an active initiation of ideas rather than a passive providing of books.

In short, there is a need for the development of a philosophy of librarianship which will probe into the complexities of its nature, discussing, enlarging, or refuting syntheses similar to the one presented in this paper.

Such a philosophy may clarify the interpretation of our purposes, thus solving the practical difficulties diagnosed sometime ago by C. O. Houle: ". . . librarians speak at cross purposes. ... They fail to understand one another because they do not appreciate in what different ways they approach a common problem. Often they do not even know how to ask one another the question which will make their differences clear, much less resolve them."2

\footnotetext{
${ }^{2}$ Cyril O. Houle, "Basic Philosophy of Library Service for Adult Education," Library Journal, LXXI (November 1, 1946), 1513.
} 